\title{
Low-molecular weight C1q-binding Immunoglobulin G in Patients with Systemic Lupus Erythematosus Consists of Autoantibodies to the Collagen-like Region of C1q
}

\author{
Shu Uwatoko and Mart Mannik \\ Division of Rheumatology, Department of Medicine, University of Washington, Seattle, Washington 98195
}

\begin{abstract}
The majority of C1q-binding IgG in sera of some patients with systemic lupus erythematosus (SLE) cosediments with monomeric IgG. This study was undertaken to provide definitive proof that the low-molecular weight C1q-binding IgG consists of autoantibodies to C1q. Monomeric C1q-binding IgG was isolated from five SLE plasmas by C1q affinity chromatography and gel filtration. All C1q-binding IgG preparations and their $\mathrm{F}\left(\mathrm{ab}^{\prime}\right)_{2}$ fragments bound to both $\mathrm{CIq}$ and the collagenlike region of C1q by an ELISA. To rule out the possibility that small DNA-antiDNA immune complexes caused this binding activity, Fab' fragments of the C1q-binding IgG preparations were digested with DNase I to degrade any DNA. The Fab' fragments continued to bind to $\mathrm{Clq}$ and its collagen-like region after this treatment. C1q-binding IgG was heterogenous on isoelectric focusing. Interaction of $\mathrm{Clq}$-binding IgG with solidphase $\mathrm{Clq}$ was retained in $1 \mathrm{M} \mathrm{NaCl}$, whereas the binding of DNA or heat-aggregated IgG to solid-phase C1q was abrogated or markedly diminished. The association constant of C1q-binding IgG with solid-phase C1q was $2.7 \times 10^{7} \mathrm{M}^{-1}$.

We conclude that low-molecular weight C1q-binding IgG in the studied patients with SLE consists of autoantibodies to the collagen-like region of $\mathrm{Clq}$.
\end{abstract}

\section{Introduction}

Systemic lupus erythematosus (SLE) ${ }^{1}$ has been considered a prototype of human diseases mediated by immune complexes.

Portions of this work were presented at the 16th Western Regional Meeting of the American Rheumatism Association, San Diego, CA, November 1987 and at the 20th Annual Meeting of the American Society of Nephrology, Washington, DC, December 1987. Portions appeared in abstract form in 1988. Arthritis Rheum. 31:R24 (Abstr.) and 1988. Kidney Int. 33:333 (Abstr.).

Address reprint requests to Dr. Shu Uwatoko, Division of Rheumatology, RG-28, Department of Medicine, University of Washington, Seattle, WA 98195.

Received for publication 29 February 1988 and in revised form 19 April 1988.

1. Abbreviations used in this paper: AHG, heat-aggregated IgG; $1 \%$ BSA-TB, TB containing $1 \%$ BSA; CFII, human Cohn fraction II; CLR, collagen-like region of $\mathrm{Clq}$; ClqSP, Clq solid-phase assay; dsDNA, double-stranded DNA; HVUS, hypocomplementemic vasculitis-urticaria syndrome; IEF, isoelectric focusing; PBS-E, $5 \mathrm{mM}$ phosphate and $0.15 \mathrm{M} \mathrm{NaCl}$, pH 7.4, containing $10 \mathrm{mM}$ EDTA; SDG, sucrose-density gradient; SLE, systemic lupus erythematosus; TB, $0.15 \mathrm{M}$ Tris$\mathrm{HCl}$ buffer, $\mathrm{pH}$ 7.6; TBS, $15 \mathrm{mM}$ Tris- $\mathrm{HCl}$ buffer and $0.15 \mathrm{M} \mathrm{NaCl}$, pH 7.6.

J. Clin. Invest.

(c) The American Society for Clinical Investigation, Inc. 0021-9738/88/09/0816/09 \$2.00

Volume 82, September 1988, 816-824
Immune deposits in tissues may arise by local formation of immune complexes or by deposition of circulating immune complexes. To detect immune complexes in circulation, a number of biological assays have been designed and used to study patients with SLE (1). The ability of immune complexes to bind to $\mathrm{Clq}$, a protein of the first component of the complement system, has been used to detect immune complexes. The C1q solid-phase assay (C1qSP) for immune complexes has been used extensively and has been suggested as a useful test for monitoring disease activity in patients with $\operatorname{SLE}(2,3)$. Several investigations have indicated that some of the Clqbinding IgG in patients with SLE is of the same size as monomeric IgG (4-6). In patients with SLE, the presence of Clqbinding IgG that cosedimented with normal IgG was related to proliferative glomerular lesions, accompanied by mesangial and subendothelial glomerular immune deposits on electron microscopy (7). Two recent observations suggested that the Clq-binding IgG, which cosediments with normal IgG, consists of autoantibodies to Clq in patients with SLE. First, the $\mathrm{F}\left(\mathrm{ab}^{\prime}\right)_{2}$ fragments of IgG containing the Clq-binding material continued to bind to $\mathrm{Clq}(5)$. Second, this material bound to the collagen-like region of Clq (CLR) rather than to the globular regions of $\mathrm{Clq}$ that are known to bind immune complexes (8).

This investigation was undertaken to isolate by affinity chromatography the C1q-binding IgG from a small number of patients with SLE and to obtain definitive proof that these IgG molecules are autoantibodies to C1q. Studies were carried out to show that small immune complexes, particularly those containing a small segment of DNA and one molecule of antibody to DNA, were not present in the isolated material. Furthermore, the isolated IgG molecules were heterogeneous on isoelectric focusing (IEF) and their binding to Clq was not consistent with charge-charge interactions. Therefore, the presented data indicate that the monomeric Clq-binding IgG in patients with SLE consists of autoantibodies directed to the collagen-like region of $\mathrm{Clq}$.

\section{Methods}

Preparation of $C l q$ and $C L R$. Clq was purified from outdated human plasma with affinity chromatography on a human IgG agarose column by the method of Kolb et al. (9). CLR was prepared by pepsin digestion of Clq (30:1, wt/wt) at $37^{\circ} \mathrm{C}$ for $20 \mathrm{~h}$ and gel filtration on Sephacryl S-300 (Pharmacia Fine Chemicals, Piscataway, NJ) as described by Reid (10). The purity and functional activity of these preparations were confirmed as previously described (8). The concentrations of Clq and CLR were determined by absorbances at $280 \mathrm{~nm}\left(E^{1 \%} / 1 \mathrm{~cm}\right.$ $=6.82)(11)$ and at $275 \mathrm{~nm}\left(\mathrm{E}^{1 \%} / 1 \mathrm{~cm}=2.1\right)(12)$, respectively.

CIqSP and CLR solid-phase assays. The solid-phase RIA were performed by a modification of the methods of Hay et al. (13) as previously described (8). In brief, Clq- or CLR-coated tubes were prepared by incubating $1 \mathrm{ml}$ of C1q or CLR solution $(5 \mu \mathrm{g} / \mathrm{ml}$ in 0.15 $\mathrm{M}$ Tris- $\mathrm{HCl}$ buffer, $\mathrm{pH} 7.6[\mathrm{~TB}])$ in polystyrene tubes $(12 \times 75 \mathrm{~mm}$, 
Falcon Labware, Becton, Dickinson \& Co., Oxnard, CA) for $2 \mathrm{~h}$ at $37^{\circ} \mathrm{C}$ and for $18 \mathrm{~h}$ at room temperature. Unreacted sites on the tubes were then covered with BSA by incubating the tubes with TB containing $1 \%$ BSA (1\% BSA-TB). $1 \mathrm{ml}$ of the test samples was added to the tubes and incubated for $2 \mathrm{~h}$ at $37^{\circ} \mathrm{C}$. The amount of IgG bound to the tubes was determined by measuring ${ }^{125}$ I-labeled $F\left(a b^{\prime}\right)_{2}$ fragments of anti-IgG retained on the tubes. Binding of IgM to solid-phase $\mathrm{Clq}$ was assayed using ${ }^{125} \mathrm{I}$-labeled $\mathrm{F}\left(\mathrm{ab}^{\prime}\right)_{2}$ fragments of goat antibodies to human $\mathrm{Fc} \mu$ (Jackson Immuno Research Laboratories, Inc., Avondale, PA).

The ELISA were performed as follows. Flat-bottomed microtiter plates (Immunoplate II; Nunc, Roskilde, Denmark) were coated by overnight incubation with Clq or CLR using $50 \mu \mathrm{l} /$ well at $20 \mu \mathrm{g} / \mathrm{ml}$ in TB. After washing three times with Tris-buffered saline (TBS, $15 \mathrm{mM}$

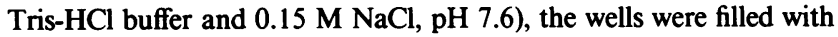
$100 \mu \mathrm{l}$ of $1 \% \mathrm{BSA}-\mathrm{TB}$ and incubated for $1 \mathrm{~h}$ at room temperature. After aspiration, samples were added at $50 \mu \mathrm{l} /$ well in $1 \%$ BSA-TB and incubated overnight at $4^{\circ} \mathrm{C}$. After being washed with TBS containing $0.1 \%$ BSA and $0.1 \%$ Triton X-100 (washing buffer), horseradish peroxidaseconjugated $F\left(a b^{\prime}\right)_{2}$ fragments of goat antibodies to human $F c \gamma$ or $\mathrm{F}\left(\mathrm{ab}^{\prime}\right)_{2 \gamma}$ (Cappel Laboratories, Malvern, PA), diluted 1:2,000 in 1\% BSA-TB were added and incubated for $4 \mathrm{~h}$ at room temperature. After a final wash, the peroxidase substrate 2,2'-azino-di-[3-ethyl-benzthiazoline sulfonate] and $\mathrm{H}_{2} \mathrm{O}_{2}$ were added and absorbance at $405 \mathrm{~nm}$ was detected on a plate reading spectrophotometer (Bio-Tek Instruments, Inc., Burlington, VT).

Clq bound to Latex beads (Latex 0.81; Difco Laboratories, Detroit, MI) was prepared for the inhibition study (described in Results) by incubating $\mathrm{Clq}$ with Latex at $4^{\circ} \mathrm{C}$ overnight and centrifuging for 15 min at 3,000 rpm and washing the Latex with $1 \%$ BSA-TB three times. The amount of $\mathrm{Clq}$ bound to Latex was quantitated using ${ }^{125} \mathrm{I}$ labeled Clq.

Isolation of Clq-binding IgG. A Clq affinity column $(1.0 \times 12.7$ $\mathrm{cm}$, containing $2.3 \mathrm{mg} \mathrm{Clq} / \mathrm{ml}$ of Sepharose CL-4B [Pharmacia Fine Chemicals]) was prepared using the protein coupling procedure previously described (14). 90-200-ml aliquots of the sera or plasmas containing $10 \mathrm{mM}$ EDTA were applied to the $\mathrm{Clq}$ affinity column, equilibrated with PBS-E ( $5 \mathrm{mM}$ phosphate and $0.15 \mathrm{M} \mathrm{NaCl}, \mathrm{pH} 7.4$ containing $10 \mathrm{mM}$ EDTA), and run at the flow rate of $4 \mathrm{ml} / \mathrm{h}$. The column was washed with PBS-E until the absorbance of the effluent was $<0.05$ at $280 \mathrm{~nm}$. The bound proteins were eluted with $1 \mathrm{M}$ sodium thiocyanate and $0.04 \mathrm{M}$ Tris- $\mathrm{HCl}, \mathrm{pH}$ 7.6. The eluates were dialyzed against PBS-E, concentrated by ultrafiltration with membranes (YM30; Amicon Corp., Danvers, MA) and divided into several aliquots. Each aliquot was applied to a $1.6 \times 90 \mathrm{~cm}$ Sephadex G-200 column, equilibrated with PBS-E, and operated at the flow rate of $8.4 \mathrm{ml} / \mathrm{h}$. The fractions were collected into four pools (I-IV), concentrated by ultrafiltration, and stored at $-70^{\circ} \mathrm{C}$. Clq-binding IgG was obtained as pool III, consisting of fractions corresponding to monomeric IgG.

$\mathrm{F}\left(\mathrm{ab}^{\prime}\right)_{2}$ fragments of Clq-binding IgG were prepared by digestion with pepsin (Worthington Diagnostics Div., Freehold, NJ) at a 1:10 pepsin/protein weight ratio for $20 \mathrm{~h}$ at $37^{\circ} \mathrm{C}$. The digestion mixtures were applied to an HPLC (Waters Associates, Millipore Corp., Milford, MA) gel filtration column (Superose 6; Pharmacia Fine Chemicals). The material eluted at the same time as control $\mathrm{F}\left(\mathrm{ab}^{\prime}\right)_{2}$ fragments and no peak corresponding to undigested IgG was detected. Fab' fragments were obtained from the $\mathrm{F}\left(\mathrm{ab}^{\prime}\right)_{2}$ fragments by reduction and alkylation of $F\left(a b^{\prime}\right)_{2}$ fragments (15). Analysis of the $F\left(a b^{\prime}\right)_{2}$ and $F a b^{\prime}$ preparations in SDS-PAGE in the presence of $10^{-4} \mathrm{M}$ iodoacetamide showed no intact IgG in either preparations and confirmed the reduction and alkylation of Fab'. The digestion of the Fab' preparation with pancreatic DNase I (Sigma Chemical Co., St. Louis, MO) to destroy any DNA that might be present was done as described by Emlen et al. (15).

IEF and immunoblotting. IEF was carried out with Pharmalytes, $\mathrm{pl}$ range 3-10 (Pharmacia Fine Chemicals) as previously described (16). Nonelectric transfer of proteins from IEF gels to nitrocellulose paper was performed by the method of Reinhart and Malamud (17). Enzyme immunodetection on nitrocellulose paper was performed essentially as described by Natori et al. (18). Briefly, after the transfer, the paper was placed in the washing buffer. After 5 min incubation at room temperature, the paper was incubated for $2 \mathrm{~h}$ at room temperature with horseradish peroxidase-conjugated goat antibodies to human $\mathrm{Fc} \gamma$ or to HSA (Cappel Laboratories), diluted 1:1,000 and 1:100 in 1\% BSA-TB, respectively, and then washed three times. Color was developed by incubating the paper with substrate solution $(0.05 \mathrm{M}$ Tris- $\mathrm{HCl}, \mathrm{pH} 7.4,0.2$ $\mathrm{M} \mathrm{NaCl}, 0.06 \%$ 4-chloro-naphthol, and $0.01 \% \mathrm{H}_{2} \mathrm{O}_{2}$ ) for 5-10 min at room temperature.

HPLC gel filtration under dissociating condition. $200 \mu \mathrm{l}$ of pool III from patient M.J. was applied to a Superose 6 column equilibrated with PBS containing $6 \mathrm{M}$ urea and $10^{-4} \mathrm{M}$ iodoacetamide. The flow rate was $0.35 \mathrm{ml} / \mathrm{min}$, and $0.53 \mathrm{ml}$ fractions were collected. The fractions were dialyzed against PBS containing $10^{-4} \mathrm{M}$ iodoacetamide. As control, an aliquot of the sample was also fractionated without $6 \mathrm{M}$ urea on the same column. Fractions from both experiments were analyzed for Clq-binding.

Other methods. Monomeric IgG, heat-aggregated IgG (AHG), HSA, rabbit antibodies to HSA, and monoclonal IgM were prepared as previously described $(14,19,20)$. Purified polyclonal human IgM (Behring Diagnostics, American Hoechst Corp., San Diego, CA), human Cohn fraction II (CF II) (Miles Scientific Div., Miles Laboratories, Inc., Naperville, IL) and antisera to human IgG, IgM, Clq, fibronectin, fibrinogen, and whole serum (Behring Diagnostics) were purchased. ${ }^{125}$ I-double-stranded DNA (dsDNA) was prepared by previously described methods (15) and generously provided by Dr. Carol Horgan (University of Washington).

Proteins except $\mathrm{Clq}$ were labeled with ${ }^{125} \mathrm{I}$ by the iodine monochloride method (21). Radioiodination of Clq was performed in lactoperoxidase-catalyzed reactions as described by Heusser et al. (22). For SDS-PAGE analysis, preformed 4-30\% polyacrylamide gradient gels (PAA 4/30; Pharmacia Fine Chemicals) were used. Quantification of IgG and IgM was performed using a sandwich immunoradiometric assay (19). Sucrose-density gradient (SDG) ultracentrifugation was performed as previously described (19). The association constant for the Clq-binding IgG interaction with solid-phase $\mathrm{Clq}$ was determined by Scatchard analysis as previously described (23). IgM rheumatoid factor was measured by an RIA as described by Wernick et al. (24).

Sera and plasmas. Plasmas were obtained from five SLE patients (S.D., G.S., J.B., M.J., and K.M.) who underwent plasmapheresis for therapeutic reasons determined by their attending physicians. Three plasmas (those of S.D., G.S., and J.B.) were converted to sera by addition of $\mathrm{CaCl}_{2}$ to a final concentration of $10 \mathrm{mM}$. On SDG ultracentrifugation of these sera and plasmas, the predominant peak of Clq-binding activity cosedimented with monomeric IgG. All patients satisfied American Rheumatism Association criteria for the classification of SLE (25). A normal plasma sample was obtained from a subject (A.J.) who underwent plasmapheresis during pregnancy due to $R \mathbf{h}$ incompatibility. The specimens were stored at $-20^{\circ} \mathrm{C}$ until used. The selection of all plasma samples was based solely on availability and no other criteria were used.

Statistical analysis. The statistical differences were analyzed by paired $t$ test.

\section{Results}

Isolation of Clq-binding IgG. Clq affinity column chromatography was used as the first step to purify Clq-binding IgG from SLE sera or plasmas. $90-200 \mathrm{ml}$ of individual specimens, containing $10 \mathrm{mM}$ EDTA, were applied to the Clq affinity column equilibrated with PBS-E. The elution of C1q affinity column with $1 \mathrm{M}$ sodium thiocyanate and $0.04 \mathrm{M}$ Tris- $\mathrm{HCl}, \mathrm{pH}$ 7.6 revealed a single peak (Fig. 1). The Clq affinity column was overloaded with each specimen since $23-63 \%$ of $\mathrm{Clq}$ binding IgG of the applied specimens remained in the fall- 


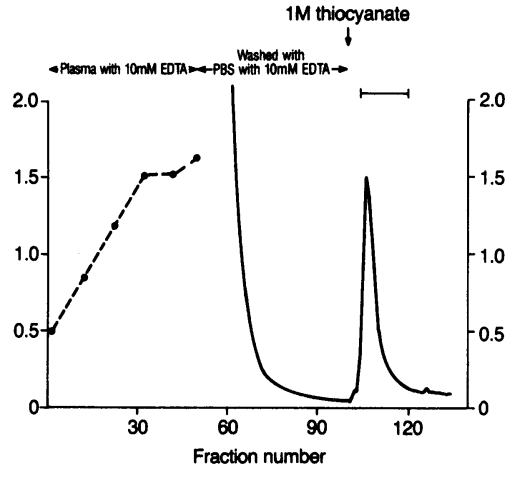

Figure 1. C1q-Sepharose CL-4B affinity chromatography of an SLE plasma. $100 \mathrm{ml}$ SLE plasma (from patient M.J.) containing $10 \mathrm{mM}$ EDTA was applied to a $1.0 \times 12.7 \mathrm{~cm}$ Clq-Sepharose CL-4B column, equilibrated with PBS-E. The flow rate of the column was $4 \mathrm{ml} / \mathrm{h}$ and two fractions were collected per hour. After being washed with PBS-E, the column was eluted with 1 $\mathrm{M}$ sodium thiocyanate and $0.04 \mathrm{M}$ Tris- $\mathrm{HCl}, \mathrm{pH}$ 7.6. Clq-binding activity $\left({ }^{125} \mathrm{I}\right.$-anti-IgG bound, $\mathrm{cpm} \times 10^{-3}$ ) of the fall-through fractions is shown by the dotted line, indicating that the column was overloaded. — , absorbance at $280 \mathrm{~nm}$. The eluted peak, designated with a bar, was processed for gel filtration.

through fractions. These calculations were based on the concentrations of Clq-binding IgG and volumes of applied materials and fall-through fractions. Furthermore, the Clq-binding IgG was decreased in initial fall-through fractions, and in later fractions the concentration of this material was the same as in the applied plasma. More than $85 \%$ of Clq-binding IgG removed from the applied sera or plasmas were recovered in the eluates. $1 \mathrm{M}$ sodium thiocyanate and $0.04 \mathrm{M}$ Tris- $\mathrm{HCl}, \mathrm{pH} 7.6$ was used for eluting the proteins bound to the C1q affinity column, because in pilot studies with SLE sera, $95.1 \%$ of IgG bound to Clq-coated polystyrene tubes was eluted from the tubes by $1 \mathrm{M}$ thiocyanate, whereas $83.1 \%$ of the bound $\operatorname{IgG}$ was eluted by $0.1 \mathrm{M}$ glycine- $\mathrm{HCl}, 0.15 \mathrm{M} \mathrm{NaCl}, \mathrm{pH} 2.5$.

As the second step of purification, gel filtration on a Sephadex G-200 column was performed to obtain monomeric Clqbinding IgG. On Sephadex G-200 gel filtration, the eluates from the Clq affinity column were resolved into two major peaks that eluted respectively in the void volume and the elution volume at which known monomeric IgG is recovered (Fig. 2). The Clq-binding IgG was centered in the second peak of protein in three specimens, and in two others the second peak of protein was not prominent. In all five specimens, however, the Clq-binding IgG peaked in the fractions corresponding to the elution volume of monomeric IgG. Four pools were created by combining the fractions of the first peak (pool I) between the first and second peaks (pool II), the second peak (pool III), and the proteins eluting after the second peak (pool IV), and concentrated. The final yields of Clq-binding IgG in pool III for the five specimens from patients with SLE were $3.5-13.0 \mu \mathrm{g} / \mathrm{ml}$ of serum or plasma applied to the $\mathrm{Clq}$ affinity column (Table I). Clq-binding IgG was also isolated from the plasma of a normal subject (A.J.), using the identical purification procedure and yielding pool III, $3.4 \mu \mathrm{g} / \mathrm{ml}$ of plasma (Table I).

IgM was detected in the first peak of the gel filtration pattern. This IgM bound to Clq comparable to purified polyclonal or monoclonal IgM. By a sensitive RIA, IgM rheumatoid factor activity was not present in the excluded peak of gel filtration.

SDS-PAGE, IEF, and immunological analysis. Purity of Clq-binding IgG in pool III from all specimens was investi-
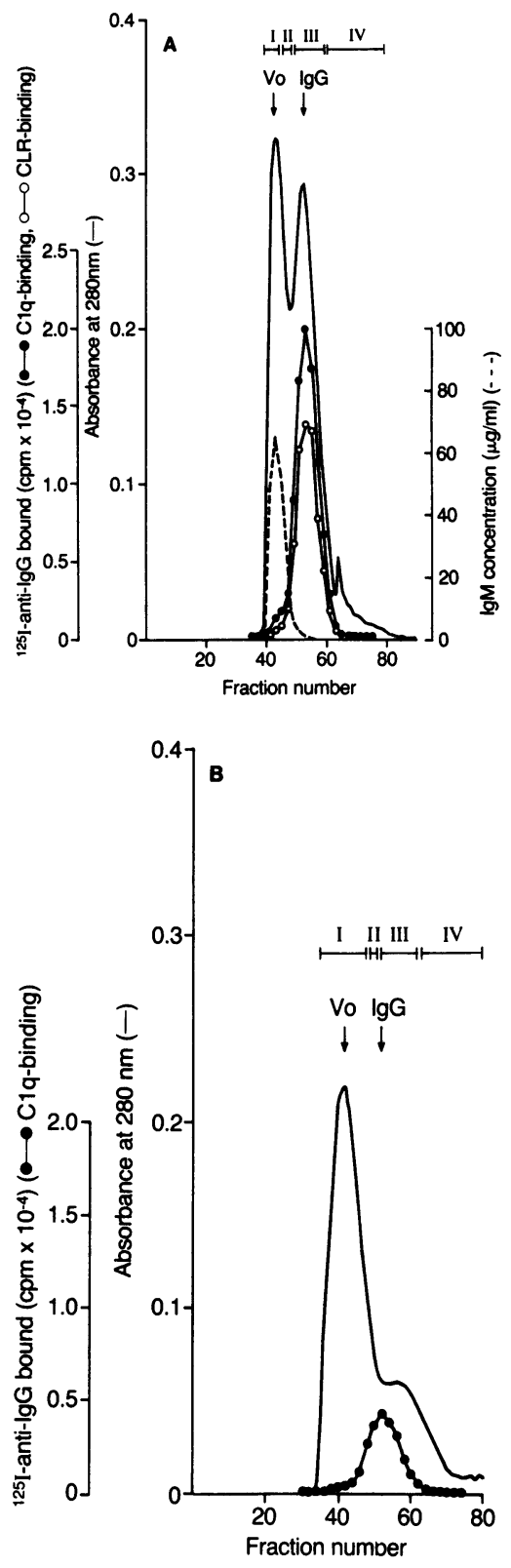

Figure 2. Sephadex G-200 gel filtration of the eluates from the C1q-Sepharose CL-4B affinity column. Eluates were dialyzed against PBS-E, concentrated by ultrafiltration, and applied to a $1.6 \times 90 \mathrm{~cm}$ Sephadex G-200 column, equilibrated with PBS-E. The flow rate was $8.4 \mathrm{ml} / \mathrm{h}$, and 2.1$\mathrm{ml}$ fractions were collected. Absorbance at $280 \mathrm{~nm}(-), \mathrm{Clq}-$ binding IgG $(-\bullet-)$, CLR-binding IgG (一O-), and concentration of IgM (- - ) are shown. Monomeric IgG is contained in pool III. $(A)$ Pattern for patient M.J. (B) Pattern for K.M.

gated by double immunodiffusion analyses in agarose, immunoelectrophoresis, and SDS-PAGE. Pool III showed a single major band corresponding to IgG on SDS-PAGE under nonreducing conditions, together with two other faint bands with apparent molecular weights of 140,000 and 67,000 (Fig. 3 , lane $B$ ). Two bands corresponding to gamma and light polypeptide chains were visualized upon reduction with 2-mercaptoethanol (Fig. 3, lane $D$ ). Double immunodiffusion and immunoelectrophoresis of pool III revealed a single precipitin line with antibodies to human IgG or antibodies to normal human serum, and no precipitin lines were seen when tested against antibodies to IgM or antibodies to HSA. ${ }^{125}$ I-labeled pool III showed a single symmetrical peak in the $7 \mathrm{~S}$ region on SDG ultracentrifugation.

SDS-PAGE analysis of pool I under nonreducing conditions exhibited several bands with apparent molecular weights larger than that of $\operatorname{IgG}$, the major band of which corresponded to IgM (Fig. 3, lane $A$ ). Several bands other than mu and light 
Table I. Yield of Clq-binding IgG from Plasma of Patients with SLE

\begin{tabular}{lcc}
\hline \multicolumn{1}{c}{ Patient } & $\begin{array}{c}\text { Clq-binding activity } \\
\text { in serum or plasma }\end{array}$ & $\begin{array}{c}\text { Amount of isolated } \\
\text { Clq-binding IgG }\end{array}$ \\
\hline & $\mu g$ AHG equivalent/ml & $\mu g /$ ml of serum or plasma \\
M.J. & 64.0 & 13.0 \\
S.D. & 7.5 & 4.5 \\
G.S. & 26.2 & 6.8 \\
K.M. & 8.3 & 3.5 \\
J.B. & 47.0 & 10.7 \\
A.J. (normal) & 5.4 & 3.4
\end{tabular}

* C1q-binding activity in serum or plasma was tested by ELISA and standardized using AHG.

polypeptide chains were present under reducing conditions (Fig. 3, lane $C$ ). Double immunodiffusion analysis of pool I showed precipitin lines with antibodies to IgM, fibrinogen, and fibronectin.

The electrophoretic heterogeneity of Clq-binding IgG was investigated to determine if charge-charge interactions might be involved in binding of anionic IgG to the relatively cationic Clq. IEF, followed by protein staining of pool III, showed a polydispersed pattern characteristic of polyclonal IgG (Fig. 4). The same results were obtained when IEF was followed by immunoblotting assay with peroxidase-conjugated antibodies to human Fcy (data not shown). By protein staining of the IEF

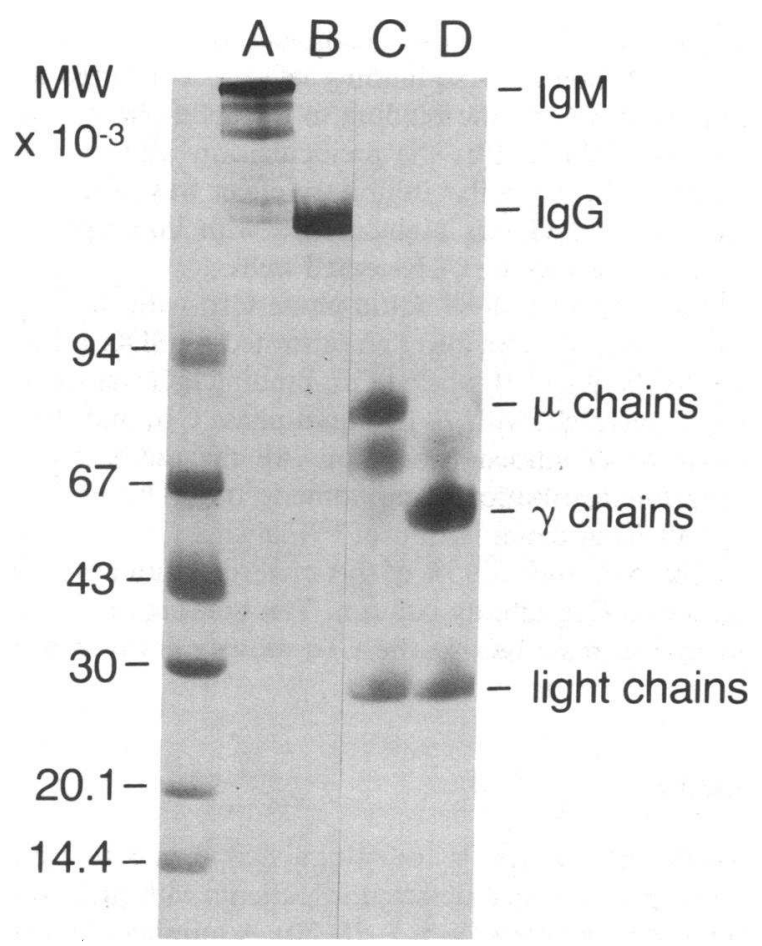

Figure 3. SDS-PAGE analysis of pool I and III from one patient (M.J.). 4-30\% gradient SDS-polyacrylamide gels were used in the presence or absence of 2-mercaptoethanol. Lane $A$, nonreduced pool I; $B$, nonreduced pool III; $C$, reduced pool I; and $D$, reduced pool III. gels, a distinct anionic band was present in all preparations of pool III and was more evident in pool IV, as illustrated with J.B. pools (Fig. 4). This anionic band was identified as HSA by immunoblotting assay, using peroxidase-conjugated antibodies to HSA for detection.

Binding characteristics of Clq-binding IgG to solid-phase $C 1 q$ or $C L R$. Pool III from all specimens was tested by ELISA for binding to C1q and CLR. All preparations of pool III bound to solid-phase C1q and CLR as detected by ELISA (Fig. 5 , Table II). $\mathrm{F}\left(\mathrm{ab}^{\prime}\right)_{2}$ preparations of pool III retained the binding activity to solid-phase C1q and CLR as detected with antibodies to $F\left(a^{\prime}\right)_{2 \gamma}$. Nearly all the values for binding of $F\left(a b^{\prime}\right)_{2}$ fragments to Clq or to CLR were higher than the binding of intact molecules, but this difference did not reach statistical significance. The increased values are attributed to the presence of antibodies to the pepsin agglutinator site in horseradish peroxidase-conjugated $\mathrm{F}\left(\mathrm{ab}^{\prime}\right)_{2}$ fragments of goat antibodies to human $F\left(a b^{\prime}\right)_{2 \gamma}$. These antibodies bind to the $F\left(a b^{\prime}\right)_{2}$ fragments, but not to the intact IgG molecules (26). The conversion of IgG molecules to $F\left(a b^{\prime}\right)_{2}$ fragments was nearly complete, since very little binding was detected with peroxidaseconjugated anti-human Fc $\gamma$.

To rule out the possible presence of immune complexes consisting of a small segment of DNA and antibodies to DNA, digestion with DNase I was used. Previous studies had shown that when antibodies to DNA were bound to DNA by monogamous bivalent binding, $\sim 40$ bp of DNA were protected from degradation by DNase and that conversion of the $F\left(a b^{\prime}\right)_{2}$ fragments to $\mathrm{Fab}^{\prime}$ fragments of the antiDNA molecules allowed degradation of the DNA by DNase I (15). Therefore, the $\mathrm{F}\left(\mathrm{ab}^{\prime}\right)_{2}$ fragments of pool III were first converted to Fab' fragments by reduction and alkylation of disulfide bonds and then treated with DNase I. The binding of Fab' fragments to Clq and to CLR was decreased, as compared with the binding of $F\left(a b^{\prime}\right)_{2}$ fragments (Table II). This decrease in binding may have resulted from decrease of the valence of the antibody molecules when converted to Fab' fragments. The treatment of the Fab' fragments with DNase, however, did not decrease their binding to C1q or to CLR. AHG bound to solid-phase C1q, but not to solid-phase CLR. Neither normal human monomeric IgG nor its $\mathrm{F}\left(\mathrm{ab}^{\prime}\right)_{2}$ and $\mathrm{Fab}^{\prime}$ fragments, all prepared from CFII, showed any binding to solid-phase Clq or CLR. In comparison, the IgG of pool III and F(ab' $)_{2}$ and Fab' fragments prepared from a normal plasma showed binding to Clq and to CLR. The yield of this material from normal plasma was less than that from most SLE plasmas.

To investigate if other unknown low-molecular weight antigens in small (e.g., $\mathrm{Ag}_{1} \mathrm{Ab}_{1}$ ) immune complexes could be responsible for the Clq-binding activity, pool III from patient M.J. was fractionated on a Superose 6 column in the presence or absence of $6 \mathrm{M}$ urea. From both experiments, the fractions were assayed for Clq-binding activity. Superimposable C1qbinding IgG distributions were found in both studies, corresponding to monomeric IgG (data not shown).

The association constant of $\mathrm{Clq}$-binding IgG with solidphase Clq was $2.7 \times 10^{7} \mathrm{M}^{-1}$, as determined by Scatchard plot analysis using ${ }^{125} \mathrm{I}$-labeled pool III from patient M.J.

The isoelectric focusing patterns, as shown above, indicated that charge-charge interactions between $\mathrm{Clq}$ and the pool III IgG isolates were unlikely because the isolated IgG preparations showed electrophoretic heterogeneity. Charge- 

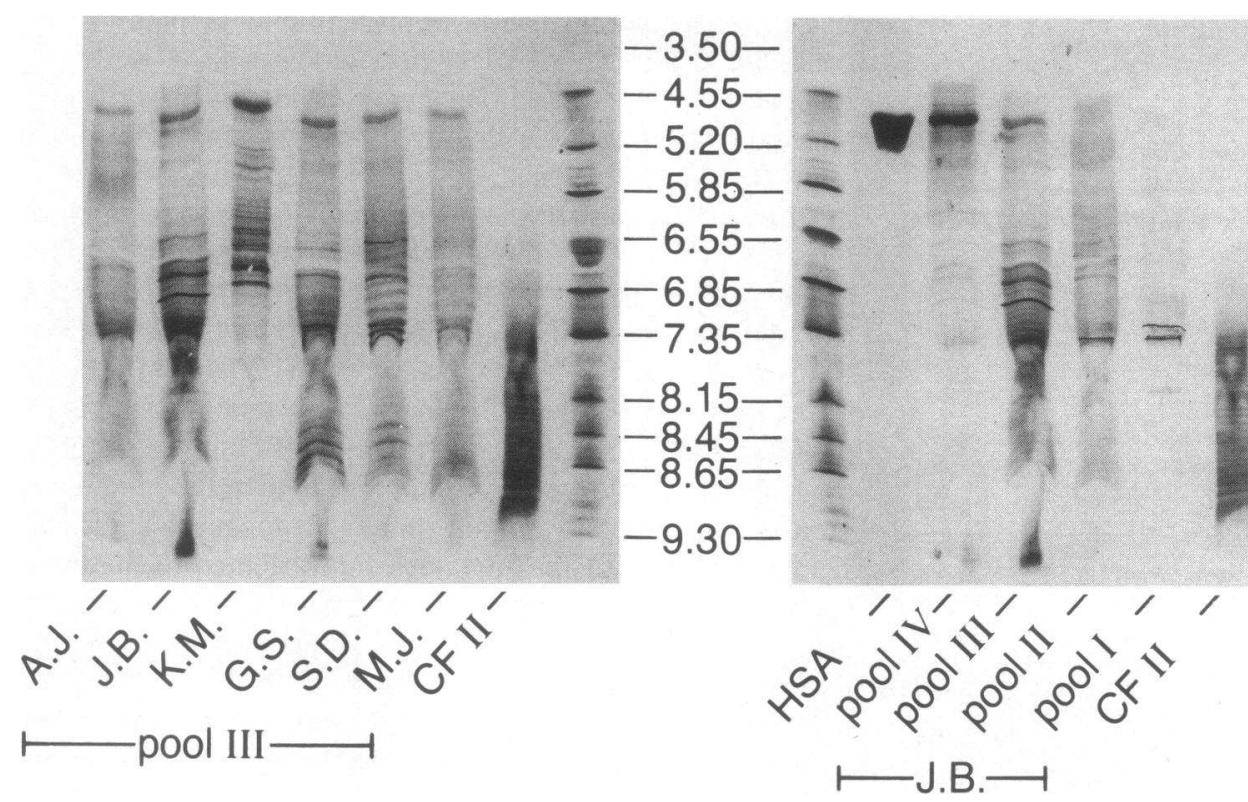

Figure 4. IEF patterns of purified Clq-binding IgG on the left and gel filtration pools from patient J.B. on the right. All preparations of pool III showed a polydispersed pattern. The anionic band seen in all preparations of pool III was more evident in pool IV, as seen in J.B. pools, and was identified as HSA. charge interactions, however, can arise from a local charge effect of a sequence of cationic amino acids in a molecule that has a total neutral charge on isoelectric focusing, as illustrated by the presence of multiple lysines in the carboxy-terminal portion of platelet factor IV (27). Therefore, the binding of pool III IgG from one patient (M.J.) to $\mathrm{Clq}$ was examined under varying salt concentrations and compared with the binding of AHG and DNA to C1q. Pool III (M.J.), AHG, and ${ }^{125} \mathrm{I}$-dsDNA were incubated with the solid-phase C1q in $5 \mathrm{mM}$ Tris- $\mathrm{HCl}$ buffer, $\mathrm{pH} 7.6$ containing various concentrations of $\mathrm{NaCl}$. The binding of ${ }^{125} \mathrm{I}-\mathrm{dsDNA}$ and AHG to solid-phase Clq was almost completely inhibited at the $\mathrm{NaCl}$ concentration of 0.25 and $1.0 \mathrm{M}$, respectively (Fig. 6). In comparison, the reactivity of pool III Clq-binding IgG with solid-phase Clq persisted at an $\mathrm{NaCl}$ concentration of $1.0 \mathrm{M}$.

Interaction of C1q-binding IgG with liquid-phase C1q. A previous study showed that the binding activity in SLE sera to

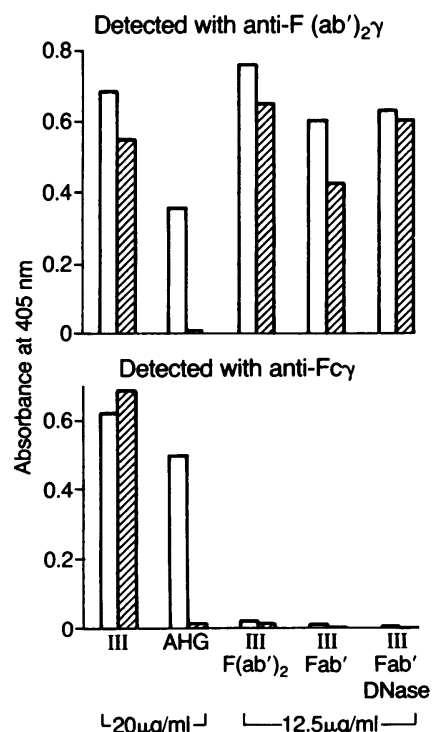

Figure 5. ELISA for binding of IgG or of IgG fragments of pool III (patient M.J.) to Clq() or CLR- (ש) coated wells. The binding of pool III to solid-phase Clq or CLR persisted after pepsin digestion as detected with antibodies to $\mathrm{F}\left(\mathrm{ab}^{\prime}\right)_{2 \gamma}($ top). The completion of digestion was determined with antibodies to $\mathrm{Fc}_{\gamma}$ (bottom). To rule out binding mediated by small DNA fragments, the Fab' fragments were treated with DNase I. the solid-phase $\mathrm{Clq}$ was not inhibited by the preincubation of the sera with liquid-phase $\mathrm{Clq}$, suggesting that $\mathrm{Clq}$-binding $\mathrm{IgG}$ is not bound to endogenous $\mathrm{Clq}(6)$. The inhibitory effect of liquid-phase $\mathrm{Clq}$ was investigated in this study using the purified Clq-binding IgG. The preincubation of $1 \mu \mathrm{g} \mathrm{Clq}-$ binding IgG with excess liquid-phase $\mathrm{Clq}(0-10 \mu \mathrm{g})$ had a limited inhibitory effect on binding of Clq-binding IgG to solid-phase $\mathrm{Clq} ; \sim 0.1 \mu \mathrm{g}$ of $\mathrm{Clq}$ was bound to individual wells, as estimated by binding of ${ }^{125} \mathrm{I}$-labeled $\mathrm{Clq}$. In comparison, Latex-bound Clq (0-5 $\mu \mathrm{g})$ caused effective inhibition. This inhibition, however, was not complete for reasons that are not known. When the Clq-binding IgG was converted to $\mathrm{Fab}^{\prime}$ fragments, however, the binding to the solid-phase $\mathrm{Clq}$ was significantly inhibited by the preincubation with liquidphase Clq (Fig. 7). A similar inhibitory effect was observed when $\mathrm{Clq}$-binding IgG was preincubated with liquid-phase CLR and then added to the CLR-coated wells.

The limited interaction of liquid-phase Clq with the isolated Clq-binding IgG was also demonstrated by SDG ultracentrifugation. $0.39 \mu \mathrm{g}{ }^{125} \mathrm{I}$-labeled Clq-binding IgG was incubated at $4^{\circ} \mathrm{C}$ overnight with $20 \mu \mathrm{g}$ liquid-phase $\mathrm{Clq}$ and then submitted to SDG ultracentrifugation. All the radioactivity remained in the distribution of monomeric IgG. This finding did not result from denaturation of ${ }^{125} \mathrm{I}$-labeled Clq-binding IgG by iodination, since $>95 \%$ of this material bound to $\mathrm{Clq}$ when applied to $\mathrm{Clq}$ affinity column. The binding of ${ }^{125} \mathrm{I}-\mathrm{la}$ beled normal human IgG to the $\mathrm{Clq}$ affinity column was $<5 \%$.

\section{Discussion}

Clq-binding IgG, which is indistinguishable in size from monomeric IgG, has been detected in patients with SLE with C1qSP by several workers (3-5, 7, 28-30). A number of possibilities have been suggested for the nature of this $\mathrm{Clq}$-binding IgG. First, an in vivo alteration of the Fc region of $\mathrm{IgG}$, which would then enhance the binding of the $\mathrm{Fc}$ region to $\mathrm{Clq}$, has been proposed $(29,30)$. This mechanism has also been sug- 
Table II. ELISA for Binding of Pool III IgG, F(ab') ${ }_{2}$ Fragments, Fab' Fragments, or DNase-treated Fab' Fragments to C1q-or CLR-Coated Wells

\begin{tabular}{|c|c|c|c|c|c|c|c|c|}
\hline \multirow[b]{2}{*}{ Patient } & \multicolumn{3}{|c|}{ Clq-binding activity } & \multirow[b]{2}{*}{$\begin{array}{c}\text { III } \\
\text { Fab' + DNase }^{-}\end{array}$} & \multicolumn{3}{|c|}{ CLR-binding activity } & \multirow[b]{2}{*}{$\begin{array}{c}\text { III } \\
\text { Fab' + DNase }^{\prime}\end{array}$} \\
\hline & III & $\underset{\mathrm{F}(\mathrm{ab})_{2}}{\text { III }}$ & $\begin{array}{l}\text { III } \\
\text { Fab' }^{\prime}\end{array}$ & & III & $\underset{F(a b)_{2}}{\text { III }}$ & $\underset{\text { III }}{\text { Fab' }}$ & \\
\hline \multirow[t]{2}{*}{ M.J. } & $0.684^{*}$ & 0.760 & 0.598 & 0.631 & 0.548 & 0.651 & 0.421 & 0.599 \\
\hline & $0.620^{*}$ & 0.020 & 0.009 & 0.007 & 0.687 & 0.013 & 0.001 & 0.000 \\
\hline \multirow[t]{2}{*}{ S.D. } & 0.646 & 0.669 & 0.476 & 0.401 & 0.546 & 0.543 & 0.166 & 0.110 \\
\hline & 0.653 & 0.033 & 0.037 & 0.025 & 0.616 & 0.023 & 0.007 & 0.014 \\
\hline \multirow[t]{2}{*}{ G.S. } & 0.764 & 0.783 & 0.624 & 0.675 & 0.645 & 0.733 & 0.554 & 0.623 \\
\hline & 0.658 & 0.019 & 0.008 & 0.011 & 0.598 & 0.019 & 0.003 & 0.008 \\
\hline \multirow[t]{2}{*}{ K.M. } & 0.604 & 0.975 & 0.459 & 0.418 & 0.612 & 1.109 & 0.347 & 0.331 \\
\hline & 0.701 & 0.040 & 0.026 & 0.032 & 0.454 & 0.033 & 0.018 & 0.018 \\
\hline \multirow[t]{2}{*}{ J.B. } & 0.555 & 0.919 & 0.424 & 0.499 & 0.551 & 0.950 & 0.520 & 0.567 \\
\hline & 0.529 & 0.023 & 0.012 & 0.010 & 0.777 & 0.020 & 0.006 & 0.012 \\
\hline \multirow[t]{2}{*}{ Mean \pm SD } & $0.651 \pm 0.080$ & $0.821 \pm 0.124^{\ddagger}$ & $0.516 \pm 0.089^{\S}$ & $0.525 \pm 0.124^{\| \prime}$ & $0.580 \pm 0.045$ & $0.797 \pm 0.230^{\ddagger}$ & $0.402 \pm 0.155^{\S}$ & $0.446 \pm 0.221^{11}$ \\
\hline & $0.632 \pm 0.064$ & $0.027 \pm 0.009$ & $0.018 \pm 0.013$ & $0.017 \pm 0.011$ & $0.626 \pm 0.119$ & $0.022 \pm 0.007$ & $0.007 \pm 0.007$ & $0.010 \pm 0.007$ \\
\hline \multirow[t]{2}{*}{ A.J. (normal) } & 0.419 & 0.561 & 0.151 & 0.140 & 0.507 & 0.812 & 0.119 & 0.138 \\
\hline & 0.717 & 0.031 & 0.025 & 0.031 & 0.457 & 0.021 & 0.009 & 0.017 \\
\hline
\end{tabular}

* Values are optical absorbance at $405 \mathrm{~nm}$. The upper and lower lines for each patient represent the data obtained with anti-F(ab') ${ }_{2 \gamma}$ and anti$F c \gamma$, respectively. ${ }^{\ddagger}$ Not significantly different as compared with the corresponding values of pool III. $\$ P<0.05$ as compared with the corresponding values of $F\left(a b^{\prime}\right)_{2}$. "Not significantly different from the corresponding values of Fab' before treatment with DNase.

gested for the low-molecular weight (7S) C1q-precipitins, encountered in patients with hypocomplementemic vasculitisurticaria syndrome (HVUS) $(30,31)$. If altered $\mathrm{Fc}$ regions of selected IgG molecules were to account for the observed Clqbinding IgG, then this activity should be lost upon pepsin digestion of the isolated molecules and the isolated Fc fragments might continue to bind to Clq. Second, Agnello et al. have suggested that DNA-antiDNA immune complexes, consisting of one antibody and one short fragment of DNA, could be responsible for this Clq-binding activity (28). This suggestion was attractive because monomers of IgG react poorly in ClqSP, but DNA that independently binds to Clq could enhance the binding of these small complexes to Clq. If small DNA-antiDNA complexes were to account for the observed Clq-binding IgG, then this activity might persist after pepsin digestion, depending on the relative contributions of the $\mathrm{Fc}$

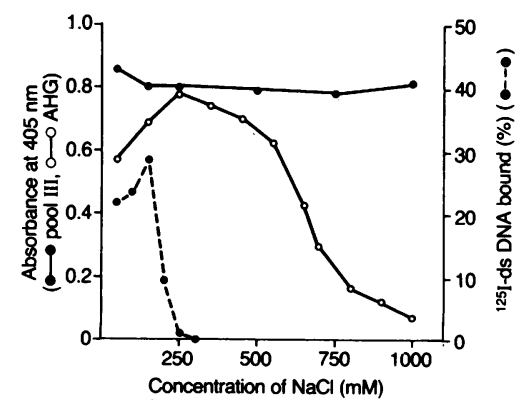

Figure 6. Effect of sodium chloride concentration on the binding of pool III IgG, AHG, and ${ }^{125}$ I-DNA to solidphase Clq. Pool III (M.J., $20 \mu \mathrm{g} / \mathrm{ml}$ ), AHG $(20 \mu \mathrm{g} / \mathrm{ml})$ and ${ }^{125} \mathrm{I}-\mathrm{ds}-$ DNA $(5 \mathrm{ng} / \mathrm{ml})$ were incubated with solidphase Clq in $5 \mathrm{mM}$ Tris- $\mathrm{HCl}$ buffer, $\mathrm{pH}$ 7.6, containing various concentrations of $\mathrm{NaCl}$. Pool III binding $(-\bullet-)$ was not disrupted by $1 \mathrm{M} \mathrm{NaCl}$, but binding of AHG $(-\circ-)$ was diminished by increasing salt concentration. The binding of dsDNA to Clq (- - - -), which is thought to be mediated by charge-charge interactions, was disrupted completely by $250 \mathrm{mM}$ $\mathrm{NaCl}$. regions or the bound DNA fragment. If the activity is retained after pepsin digestion, then conversion of the $F\left(a b^{\prime}\right)_{2}$ fragments to Fab' fragments and digestion with DNase would abrogate the binding to Clq. Third, theoretically, other small antigenantibody complexes could account for the low-molecular weight $\mathrm{Clq}$ binding. Fourth, anionic IgG molecules could bind to the relatively cationic $\mathrm{Clq}$ entirely by charge-charge interactions. This property would reside mainly in the $F\left(a b^{\prime}\right)_{2}$ fragments, because of the presence of the variable regions in the $\mathrm{IgG}$ molecule. Finally, another possibility is that the Clq-binding IgG represents antibodies directed against $\mathrm{Clq}(5)$.

In this study, Clq-binding IgG was purified by $\mathrm{Clq}$ affinity chromatography and gel filtration. Monomeric Clq-binding IgG was obtained as the second peak on gel filtration of the eluates from the $\mathrm{Clq}$ affinity column. Monomeric IgG eluted from the $\mathrm{Clq}$ affinity column bound avidly to the $\mathrm{Clq}$ affinity column when reapplied to it.

The binding of the $\mathrm{F}\left(\mathrm{ab}^{\prime}\right)_{2}$ fragments, prepared from Clq-

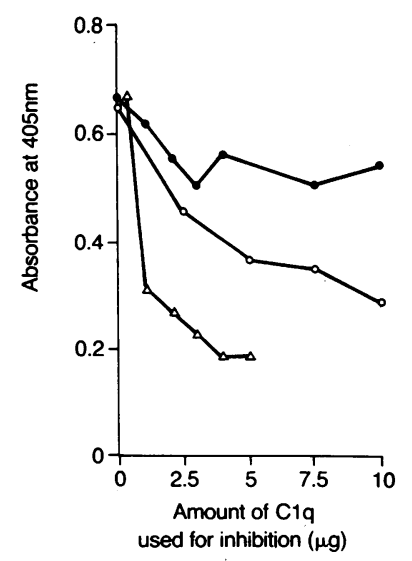

Figure 7. Inhibition of the binding of pool III (M.J.) IgG to the solidphase $\mathrm{Clq}$ by liquid-phase $\mathrm{Clq}$. Pool III (M.J., $1 \mu \mathrm{g})(-\bullet-)$ and its Fab' $(0.625 \mu \mathrm{g})(-\circ-)$ were preincubated with various amounts of liquid-phase $\mathrm{Clq}$ $(0-10 \mu \mathrm{g})$ at $4^{\circ} \mathrm{C}$ overnight and then added to the Clq-coated wells. Progressive inhibition of only Fab' fragments is evident. In comparison, when pool III (M.J., $1 \mu \mathrm{g})$ was preincubated with Latex-bound Clq $(0-5 \mu \mathrm{g})$ $(-\Delta-)$, effective inhibition was found. 
binding IgG, to C1q or CLR was clearly not due to DNAantiDNA immune complexes, which would bind to $\mathrm{Clq}$ via DNA. The DNase digestion did not decrease the binding activity of Fab' preparations to solid-phase C1q or CLR. The binding of dsDNA to Clq also decreased markedly by raising the ionic strength, which is consistent with the results obtained by van Schravendijk and Dwek (32). In comparison, the binding activity of $\mathrm{Clq}$-binding $\mathrm{IgG}$ was not decreased by even $1 \mathrm{M}$ $\mathrm{NaCl}$. Furthermore, it has been suggested that the globular region of $\mathrm{Clq}$, rather than CLR, is involved in DNA binding (32). The presence of small Clq-binding immune complexes was ruled out by the gel filtration experiment in $6 \mathrm{M}$ urea. If immune complexes had been present, they must have contained a small antigen molecule and one antibody molecule, because at neutral $\mathrm{pH}$, the isolated $\mathrm{Clq}$-binding material possessed the size characteristics of monomeric IgG. Therefore, gel filtration in $6 \mathrm{M}$ urea should have dissociated and separated from IgG a small antigen molecule. The results thus strongly argue that small immune complexes with an unknown antigen were not present.

The purified Clq-binding IgG did not consist of anionic IgG. Furthermore, studies with increasing concentrations of added salt ruled out charge-charge interactions between $\mathrm{Clq}$ and the isolated $\mathrm{IgG}$.

The presented results thus show that the Clq-binding IgG in sera of patients with SLE consists of antibodies to Clq, directed against the CLR. Previous investigators had concluded that the observed phenomenon was not a result of antibodies to Clq. Agnello et al. detected 7S Clq-precipitins in SLE sera by double immunodiffusion assay (33). They dismissed the possibility of the presence of antibodies to $\mathrm{Clq}$ because, in one carefully studied patient, the binding of the 7S material to $\mathrm{Clq}$ was lost when the IgG was reduced and alkylated (33). In our studies, however, the Clq-binding activity persisted after reduction and alkylation and after conversion to $\mathrm{F}\left(\mathrm{ab}^{\prime}\right)_{2}$ fragments (5). Marder et al. purified 7S C1 q-precipitins in SLE by using C1q-coated polystyrene beads, elution with 20 mM citrate buffer, $\mathrm{pH} 3.2$, followed by Staphylococcal protein A affinity chromatography (30). They characterized the isolated 7S Clq-precipitins as a monomeric polyclonal IgG. On the basis of their earlier work, these authors suggested that the binding of IgG to $\mathrm{Clq}$ occurred by the $\mathrm{Fc}$ fragment. In that earlier study, the authors showed that 7S C1q-precipitins in HVUS lost the Clq-binding activity after pepsin digestion (31). The reasons for the loss of C1q-precipitating activity by these previous investigations are not entirely clear. The test system obviously was less sensitive than the C1q-binding assay used in this report. The methods were different and the previously studied specimens were obtained from patients with HVUS and not from patients with SLE.

Clq-binding IgG was also obtained in a small quantity from the plasma of an normal subject (A.J.). The Fab' fragments of Clq-binding IgG from A.J., however, showed a markedly reduced binding activity to Clq and CLR, as compared with those of the Fab' preparations of SLE patients. This finding suggests that antibodies to Clq also can occur in normal persons, but they may differ from those found in patients with SLE. The prevalence of antibodies to CLR among normal persons, however, has not been determined.

Previous reports indicated that the Clq-precipitins and $\mathrm{Clq}$-binding IgG possessed preferential binding to $\mathrm{Clq}$ bound to a solid-phase $(6,29,30)$, presumably resulting from exposure of antigenic determinants not present on liquid-phase Clq (30). Alternatively, preferential binding of antibodies to $\mathrm{Clq}$ in solid-phase may arise as a result of multivalent interaction with the C1q adherent to a surface (29). The presented results supported both possibilities. Radiolabeled Clq-binding IgG did not form complexes in liquid-phase, as determined by SDG ultracentrifugation. In addition, a large excess of liquidphase Clq did not significantly inhibit the binding of antibodies to Clq to the solid-phase Clq or CLR, whereas Latexbound $\mathrm{Clq}$ was an effective inhibitor. All of these findings support the notion that new antigenic determinants are exposed on C1q molecules when they become attached to a solid surface. On the other hand, when the antibodies to Clq were converted to univalent $\mathrm{Fab}^{\prime}$ fragments, liquid-phase $\mathrm{Clq}$ was able to inhibit binding of these molecules to solid-phase $\mathrm{Clq}$, albeit not very effectively. In vivo, the binding of the described antibodies to circulating $\mathrm{C1q}$ may be inhibited by the presence of $\mathrm{Clr}$ and $\mathrm{Cls}$, which also bind to the CLR of the C1q molecule.

The IgM in the excluded protein peak on gel filtration bound to $\mathrm{Clq}$ in solid-phase comparable to pooled, normal human IgM and to a Waldenström's macroglobulin. Previous studies have shown that IgM molecules bind to $\mathrm{Clq}$ better than IgG molecules (34). Therefore, the available information does not argue for the presence of IgM antibodies to C1q. The reasons for the presence of fibrinogen and fibronectin in this fraction have not been examined. Interestingly, despite careful washing of the Clq columns before elution, small amounts of HSA were present in the eluate. This HSA was isolated from one pool III by affinity chromatography and did not differ from normal HSA on SDS-PAGE and on IEF. Furthermore, purified HSA did not bind to the Clq column. The binding of HSA to IgM or IgA by intermolecular disulfide bonds was excluded by showing that when the isolations were carried out in the presence of $10^{-4} \mathrm{M}$ iodoacetamide, the HSA remained in monomeric distribution. This procedure had previously been used to prevent cleavage of intermolecular disulfide bonds between HSA and IgA or IgM (35).

Antibodies to Clq can contribute to the pathogenesis of glomerulonephritis in patients with SLE by several mechanisms. Wener et al. found that the presence of large amounts of Clq-binding 6.6S IgG in serum is associated with proliferative lupus nephritis and that there is a significant negative correlation between the presence of this C1q-binding IgG and subepithelial electron-dense deposits (7). Immune complexes that have deposited in the subendothelial area and have bound Clq can be stabilized further by antibodies to $\mathrm{Clq}$ and therefore remain in the subendothelial area. Greisman et al. have reported that in patients with SLE the presence of Clq in circulating immune complexes correlates with the presence of renal disease (36). Clq may bind to immune complexes in circulation. Alternatively, immune complexes may form in circulation between antibodies to $\mathrm{Clq}$ and $\mathrm{Clq}$ molecules that have exposed antigenic determinants for these antibodies. Interestingly, deposits of $\mathrm{Clq}$ are seen more frequently in lupus nephritis than in other glomerulonephropathies $(37,38)$. Antibodies to Clq may not be confined to patients with SLE since Strife et al. have recently demonstrated that Clq-binding IgG in serum from patients with membranoproliferative glomerulonephritis most likely represents antibodies to a cryptic anti- 
gen revealed when $\mathrm{Clq}$ is bound to a solid surface (39). Further studies should clarify the contributions of antibodies to Clq to the pathogenesis of lupus nephritis.

\section{Acknowledgments}

We would like to thank Dr. Mark Wener for providing the plasmas obtained by plasmapheresis. The able technical assistance of Susan A. Stapleton and Frances Barbara Martin and skilled word processing of Linny Simkin are gratefully acknowledged.

This work was supported by research grant AR-11476 from the National Institute of Arthritis, Musculoskeletal, and Skin Diseases, a grant from The Lupus Foundation of America, Inc., and a grant-in-aid from the Mochida Memorial Foundation for Medical and Pharmaceutical Research, Tokyo, Japan. Dr. Uwatoko received a Fulbright Scholarship.

\section{References}

1. Theofilopoulos, A. N., and F. J. Dixon. 1979. The biology and detection of immune complexes. Adv. Immunol. 28:89-220.

2. Abrass, C. K., K. M. Nies, J. S. Louie, W. A. Border, and R. J. Glassock. 1980. Correlation and predictive accuracy of circulating immune complexes with disease activity in patients with systemic lupus erythematosus. Arthritis Rheum. 23:273-282.

3. Tung, K. S. K., R. J. DeHoratius, and R. C. Williams, Jr. 1981. Study of circulating immune complex size in systemic lupus erythematosus. Clin. Exp. Immunol. 43;615-625.

4. Robinson, M. F., J. L. Roberts, J. V. Jones, and E. J. Lewis. 1979. Circulating immune complex assays in patients with lupus and membranous glomerulonephritis. Clin. Immunol. Immunopathol. 14:348-360.

5. Uwatoko, S., S. Aotsuka, M. Okawa, Y. Egusa, R. Yokohari, C. Aizawa, and K. Suzuki. 1984. Characterization of Clq-binding IgG complexes in systemic lupus erythematosus. Clin. Immunol. Immunopathol. 30:104-116.

6. Uwatoko, S., S. Aotsuka, M. Okawa, Y. Egusa, R. Yokohari, C. Aizawa, and K. Suzuki. 1984. Clq solid-phase radioimmunoassay: binding properties of solid-phase $\mathrm{Clq}$ and evidence that $\mathrm{Clq}$-binding IgG complexes in systemic lupus erythematosus are not bound to endogenous C1q. J. Immunol. Methods. 73:67-74.

7. Wener, M. H., M. Mannik, M. M. Schwartz, and E. J. Lewis. 1987. Relationship between renal pathology and the size of circulating immune complexes in patients with systemic lupus erythematosus. Medicine (Baltimore). 66:85-97.

8. Uwatoko, S., S. Aotsuka, M. Okawa, Y. Egusa, R. Yokohari, C. Aizawa, and K. Suzuki. 1987. Clq solid-phase radioimmunoassay: evidence for detection of antibody directed against the collagen-like region of $\mathrm{Clq}$ in sera from patients with systemic lupus erythematosus. Clin. Exp. Immunol. 69:98-106.

9. Kolb, W. P., L. M. Kolb, and E. R. Podack. 1979. Clq: isolation from human serum in high yield by affinity chromatography and development of a highly sensitive hemolytic assay. J. Immunol. 122:2103-2111.

10. Reid, K. B. M. 1976. Isolation, by partial pepsin digestion, of the three collagen-like regions present in subcomponent $\mathrm{Clq}$ of the first component of human complement. Biochem. J. 155:5-17.

11. Reid, K. B. M., D. M. Lowe, and R. R. Porter. 1972. Isolation and characterization of $\mathrm{Clq}$, a subcomponent of the first component of complement, from human and rabbit sera. Biochem. J. 130:749763.

12. Siegel, R. C., and V. N. Schumaker. 1983. Measurement of the association constants of the complexes formed between intact Clq or pepsin-treated Clq stalks and the unactivated or activated $\mathrm{Cl}_{2} \mathrm{Cls}_{2}$ tetramers. Mol. Immunol. 20:53-66.

13. Hay, F. C., L. J. Nineham, and I. M. Roitt. 1976. Routine assay for the detection of immune complexes of known immunoglobulin class using solid phase Clq. Clin. Exp. Immunol. 24:396-400.

14. Mannik, M., W. P. Arend, A. P. Hall, and B. C. Gilliland. 1971. Studies on antigen-antibody complexes. I. Elimination of soluble complexes from rabbit circulation. J. Exp. Med. 133:713-739.

15. Emlen, W., R. Ansari, and G. Burdick. 1984. DNA-anti-DNA immune complexes. Antibody protection of a discrete DNA fragment from DNase digestion in vitro. J. Clin. Invest. 74:185-190.

16. Gauthier, V. J., M. Mannik, and G. E. Striker. 1982. Effect of cationized antibodies in preformed immune complexes on deposition and persistence in renal glomeruli. J. Exp. Med. 156:766-777.

17. Reinhart, M. P., and D. Malamud. 1982. Protein transfer from isoelectric focusing gels: the native blot. Anal. Biochem. 123:229-235.

18. Natori, Y., I. Hayakawa, and S. Shibata. 1986. Passive Heymann nephritis with acute and severe proteinuria induced by heterologous antibody against renal tubular brush border glycoprotein gp108. Lab. Invest. 55:63-70.

19. Wener, M. H., and M. Mannik. 1985. Selective losses of large immune complexes during density gradient ultracentrifugation and an approach for prevention of these losses. J. Immunol. Methods. 84:1-10.

20. Oppliger, I. R., F. A. Nardella, G. C. Stone, and M. Mannik. 1987. Human rheumatoid factors bear the internal image of the Fc binding region of Staphylococcal protein A. J. Exp. Med. 166:702710 .

21. Helmkamp, R. W., R. L. Goodland, W. F. Bale, I. L. Spar, and L. E. Mutschler. 1960. High specific activity iodination of $\gamma$-globulin with iodine-131 monochloride. Cancer Res. 20:1495-1500.

22. Heusser, C., M. Boesman, J. H. Nordin, and H. Isliker. 1973. Effect of chemical and enzymatic radioiodination on in vitro human Clq activities. J. Immunol. 110:820-828.

23. Nelson, J. L., F. A. Nardella, and M. Mannik. 1985. Competition between antigen and anti-idiotypes for rheumatoid factors. $J$. Immunol. 135:2357-2361.

24. Wernick, R., J. J. LoSpalluto, C. W. Fink, and M. Ziff. 1981. Serum IgG and IgM rheumatoid factors by solid phase radioimmunoassay. A comparison between adult and juvenile rheumatoid arthritis. Arthritis Rheum. 24:1501-1511.

25. Tan, E. M., A. S. Cohen, J. F. Fries, A. T. Masi, D. J. McShane, N. F. Rothfield, J. G. Schaller, N. Talal, and R. J. Winchester. 1982. The 1982 revised criteria for the classification of systemic lupus erythematosus. Arthritis Rheum. 25:1271-1277.

26. Osterland, C. K., M. Harboe, and H. G. Kunkel. 1963. Anti- $\gamma-$ globulin factors in human sera revealed by enzymatic splitting of antiRh antibodies. Vox Sang. 8:133-152.

27. Handin, R. I., and H. J. Cohen. 1976. Purification and binding properties of human platelet factor four. J. Biol. Chem. 251:42734282.

28. Agnello, V., and T. Mitamura. 1982. Evidence for detection of low molecular weight DNA-anti-DNA complexes in systemic lupus erythematosus. Arthritis Rheum. 25:788-792.

29. Hack, C. E., and A. J. M. Belmer. 1986. The IgG detected in the Clq solid-phase immune-complex assay is not always of immune complex nature. Clin. Immunol. Immunopathol. 38:120-128.

30. Marder, R. J., L. A. Potempa, J. V. Jones, D. Toriumi, F. R. Schmid, and H. Gewurz. 1984. Assay, purification and further characterization of $7 \mathrm{~S} \mathrm{Clq-precipitins} \mathrm{(Clq-p)} \mathrm{in} \mathrm{hypocomplementemic} \mathrm{vas-}$ culitis urticaria syndrome and systemic lupus erythematosus. Acta Pathol. Microbiol. Immunol. Scand. (Sect. C. Immunol. Suppl. 284) 92:25-34.

31. Marder, R. J., F. X. Burch, F. R. Schmid, C. R. Zeiss, and H. Gewurz. 1978. Low molecular weight Clq-precipitins in hypocomplementemic vasculitis-urticaria syndrome: partial purification and characterization as immunoglobulin. J. Immunol. 121:613-618. 
32. van Schravendijk, M. R., and R. A. Dwek. 1982. Interaction of Clq with DNA. Mol. Immunol. 19:1179-1187.

33. Agnello, V., D. Koffler, J. W. Eisenberg, R. J. Winchester, and H. G. Kunkel. 1971. Clq precipitins in the sera of patients with systemic lupus erythematosus and other hypocomplementemic states. Characterization of high and low molecular weight types. J. Exp. Med. $134: 228 \mathrm{~s}-241 \mathrm{~s}$.

34. Sledge, C. R., and D. H. Bing. 1973. Binding properties of the human complement protein Clq. J. Biol. Chem. 248:2818-2823.

35. Mannik, M. 1967. Binding of albumin to $\gamma$ A-myeloma proteins and Waldenström macroglobulins by disulfide bonds. J. Immunol. 99:899-906.
36. Greisman, S. G., P. B. Redecha, R. P. Kimberly, and C. L. Christian. 1987. Differences among immune complexes: association of $\mathrm{Clq}$ in SLE immune complexes with renal disease. J. Immunol. 138:739-745.

37. Lewis, E. J., G. J. Busch, and P. H. Schur. 1970. Gamma G globulin subgroup composition of the glomerular deposits in human renal diseases. J. Clin. Invest. 49:1103-1113.

38. Jennette, J. C., and C. G. Hipp. 1985. Immunohistopathologic evaluation of Clq in 800 renal biopsy specimens. Am. J. Clin. Pathol. 83:415-420.

39. Strife, C. F., K. Forshey, A. Kleesattel, and D. Hauck. 1987. Circulating antibody to solid phase $\mathrm{Clq}$ in patients with membranoproliferative glomerulonephritis. Kidney Int. 31:331. (Abstr.) 